\title{
Numerical Simulation Study on the Detection of Weak Structural Plane of Rock Slope by Using 3D Electrical Resistivity Tomography
}

\author{
Xin Zhang \\ School of River \& Ocean Engineering, Chongqing Jiaotong University, Chongqing, China \\ Email: 406328338@qq.com
}

Received 30 June 2016; accepted 22 July 2016; published 25 July 2016

Copyright (C) 2016 by author and Scientific Research Publishing Inc. This work is licensed under the Creative Commons Attribution International License (CC BY). http://creativecommons.org/licenses/by/4.0/

\begin{abstract}
The weak structure plane is an important factor affecting the stability of rock slope, and detecting the spatial structure of the weak structural plane is beneficial to analyze the stability of the slope and estimate the quantity of the landslide. Based on 3D electrical resistivity tomography, a model of rock slope with weak structure plane is established, and the characteristics of three-dimensional resistivity imaging of weak structure plane under different ground water conditions are simulated. The results show that the weak structural plane has a better reflection in 3D electrical resistivity tomography; the distribution of weak structural plane of 3D resistivity imaging can be roughly determined under different ground water conditions; the three-dimensional electrical resistivity tomography is feasible in the detection of weak structural plane of rock slope.
\end{abstract}

\section{Keywords}

Rock Slope, Soft Structure Plane, 3D Electrical Resistivity Tomography, Numerical Simulation

\section{Introduction}

China is a mountainous country; the mountainous area of our country accounts for over $50 \%$ of the total land area; the problems of geological disasters occur frequently; the problem of slope instability is particularly prominent, which poses a threat to people's lives. So it is very important to study the stability of the slope in the design and construction of the slope engineering. Weak structural plane is formed in the rock mass with a certain extending direction and length; thickness is relatively small geological interface; it includes material interfaces 
and discontinuities, such as level and unconformity face, joints and faults and so on. The weak structure plane in a large scale, such as low intensity, easy deformation, often influences the integrity, permeability, physical mechanical properties and stress transfer of engineering rock mass, which is one of the essential causes of non-homogeneous, non-continuous, anisotropic and non-linear elasticity of rock mass [1]. The development of weak structure plane is often the main cause of landslide, so it is very important to understand the scale of the weak structure plane in time, which plays an important role in the analysis of the stability of the slope.

Drilling as a traditional geological prospecting method cost is high, and blind. In order to find out the geological condition quickly and accurately, the high density resistivity is a new geophysical prospecting method. Two-dimensional high density resistivity method development has been relatively mature, proposed by Japanese scholars in the eighties of the twentieth century; the high density resistivity method can collect data automatically, measure quickly, get a lot of information, draw 2D profile image and reflect the geoelectric structure fully; the method is superior to the traditional electrical method [3]. The ideal electrical models proposed by Gou Xiujun [2] are given to figure slide-face in homogeneous soil slope, soft interlayer, and geological structure. Two dimensional apparent resistivity sections are formed with finite element method corresponding to four kinds of routine in-situ data collecting arrays, which are Wenner array, Schlumberger array, dipole-dipole array and pole-pole array. The ideal electric array and abnormal resistivity pattern are determined by analyzing the sections. Taking actual engineering as example, Chen Jing [4] has introduced key technical problems and handling methods of cause analysis of applying high density electric prospecting technique to expressway slope landslide. It is proved by practice that high density electric prospecting technique can achieve accurate result in slope landslide exploration which provided reliable reference for developing expressway landslide treatment measures. Although the three-dimensional electrical resistivity tomography is not mature, there are still many problems need further study; but compared with the two-dimensional high density resistivity method, the three-dimensional resistivity imaging can obtain more abundant data; the underground geoelectric perspective and the measuring range are more extensive. Based on the engineering example, Hermann Zeyen [5] used the three-dimensional resistivity imaging technique to obtain the resistivity distribution which also allows locating the Masterton strike-slip fault just north of the mud volcano field and confirming the role of this fault as conduit of the mud from deeper layers to the surface. The three-dimensional model of rock slope is established to study the spatial distribution of the weak structure plane under different groundwater conditions, which lays a foundation for promoting the development of three-dimensional electrical resistivity tomography.

\section{Theory of 3D Electrical Resistivity Tomography}

The three-dimensional electrical resistivity tomography is based on the difference of the underground medium resistivity, through the electrode to the underground power, to measure the different points of apparent resistivity in underground, apparent resistivity value is not a specific point resistivity values, but a comprehensive reflection of a regional resistivity and apparent resistivity calculation formula is:

$$
\rho=k \frac{\Delta U}{I}
$$

where: $\rho$ is the apparent resistivity; $k$ is the coefficient of the device; $\Delta U$ is the potential difference; $I$ is the current.

The core of 3-D resistivity tomography is forward modeling and inversion. The forward modeling is known geoelectric model and field source distribution, distributed of electric field problem is solved. Inversion is to find a geoelectrical model and enable the corresponding values of theoretical calculation and measured apparent resistivity values coincide with the best under certain rules. Forward modeling is the base of the inversion, and the theoretical value of the forward calculation is obtained. Inversion calculation is often the underground space is divided into several small cuboids, in comparing the theoretical value and the measured value during the process, the Jacobian matrix calculation is the core and the calculation method is generally divided into Gauss Seidel method and quasi Newton method, Gauss Seidel method in every iteration needs to compute the Jacobian matrix and long computing time, high precision and quasi Newton method do not need every time to calculate the Jacobian matrix, only need a calculation, back calculated by iterative formula, fast calculation and low precision. Modification of model parameters is for computational purposes. After reaching the accuracy, will give the theoretical value of each cuboid, get the final geoelectric structure [6]. 


\section{Numerical Simulation}

When there is ground water in the weak structure plane, it is generally low resistance. The joints have strong joint development or discontinuous surface in the weak structure plane, and the resistance is generally higher when there is no water [7]. Setting two rock slope models are built to simulate the resistivity characteristics of the weak structure plane with different groundwater conditions. the weak structure plane distance from the slope $2 \mathrm{~m}$, thick $0.5 \mathrm{~m}$, long $12 \mathrm{~m}$, wide $10 \mathrm{~m}$, the establishment of the model as shown in Figure 1 . In order to maintain consistency with the actual test, assuming that the simulation use Chongqing Geological Instrument Factory production of duk-2b electrical instrument to collect data and acquisition mode selection of Wenner device, electrode using $17 \times 17$ arrangement, 1m distance, measuring line layout style such as shown in Figure 2 .

\subsection{The Resistivity Characteristics of Weak Structure Plane Underground Water}

When there is groundwater, assuming the resistivity of surface covering layer is $50 \Omega \cdot \mathrm{m}$, the weak structural plane is $5 \Omega \cdot \mathrm{m}$, the bedrock is $100 \Omega \cdot \mathrm{m}$. Numerical simulation results are shown in Figure 3. From XY resistivity distribution diagram can be found to a significantly low resistivity anomaly area and weak structural plane where corresponds to the position, and was a rectangular shape, about $12 \mathrm{~m}$ length, about $10 \mathrm{~m}$ wide, the result is consistent with the model, indicating that low resistance patterns of the weak structure plane reflected well. From the XZ resistivity distribution diagram shows that the low resistance anomaly area is about $10 \mathrm{~m}$ wide, and the thickness has some error, the shape of the low resistivity anomaly area is basically the same as the position and size of the weak structure plane. From YZ resistivity distribution figure seen, low resistivity anomaly mayor $12 \mathrm{~m}$ length, thickness of some error, but low resistivity zone and weak structural plane where position corresponding. In general, the low resistivity in the middle, high on both sides, and like a ring distribution, can be roughly determine the boundaries of the cover, the weak structure plane and bedrock, so as to calculate the size of the weak structure plane. The results show that the low resistance characteristic of the weak structure plane under the action of groundwater is obvious, and the effect is good.

\subsection{The Resistivity Characteristics of Weak Structure Plane without Ground Water}

The action is without groundwater, assuming the resistivity of surface covering layer is $10 \Omega \cdot \mathrm{m}$, the weak structural plane is $100 \Omega \cdot \mathrm{m}$, the bedrock is $50 \Omega \cdot \mathrm{m}$. Numerical simulation results are shown in Figure 4 . From the

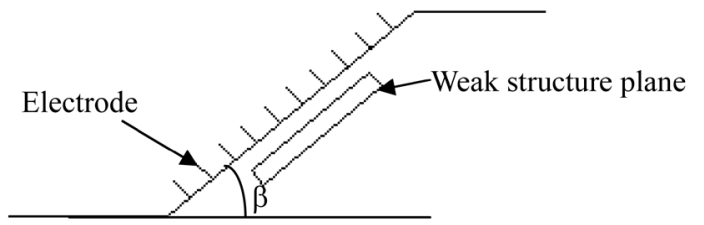

Figure 1. Slope model.

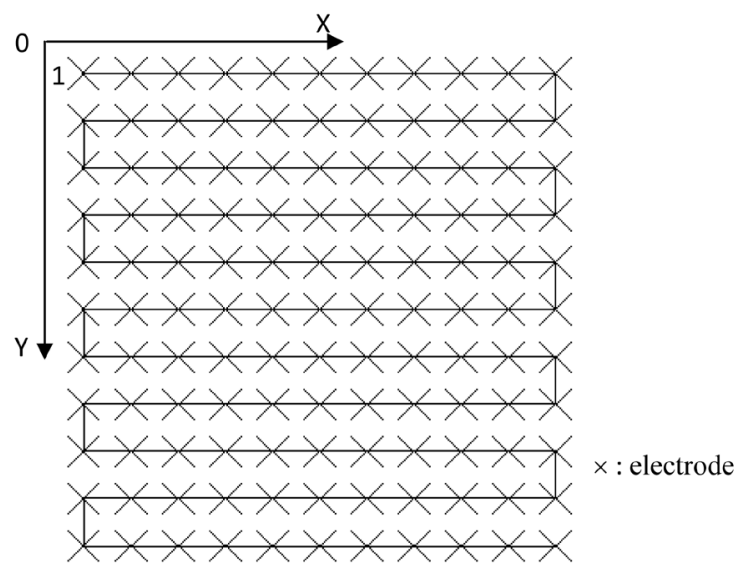

Figure 2. Layout of measuring line. 

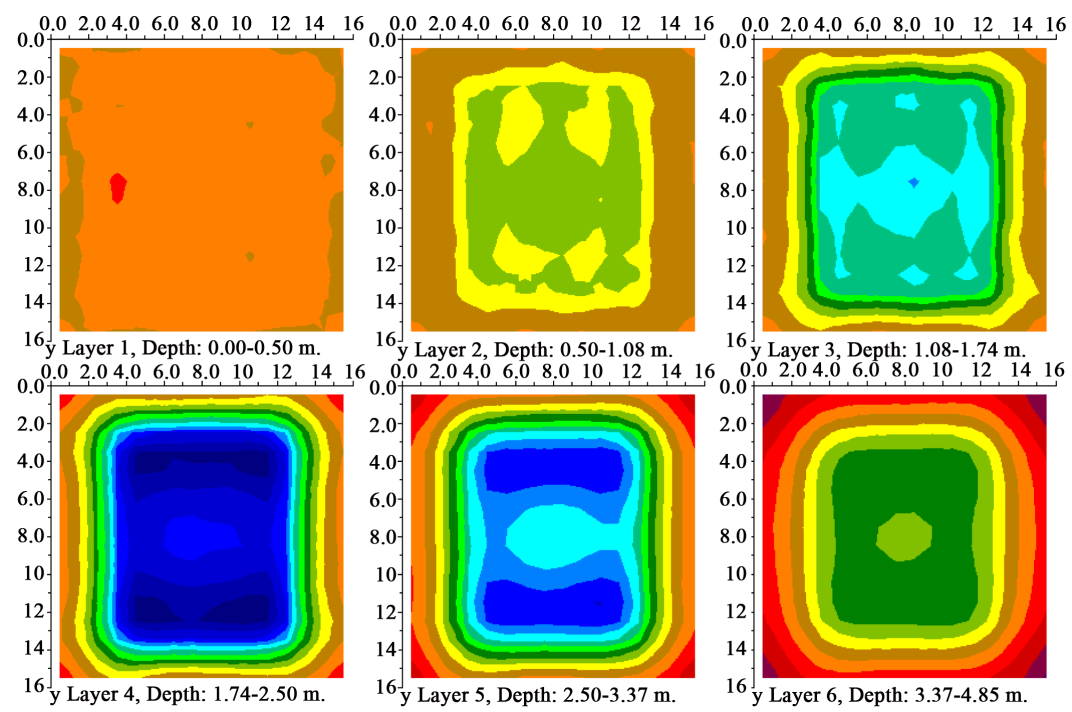

(a)

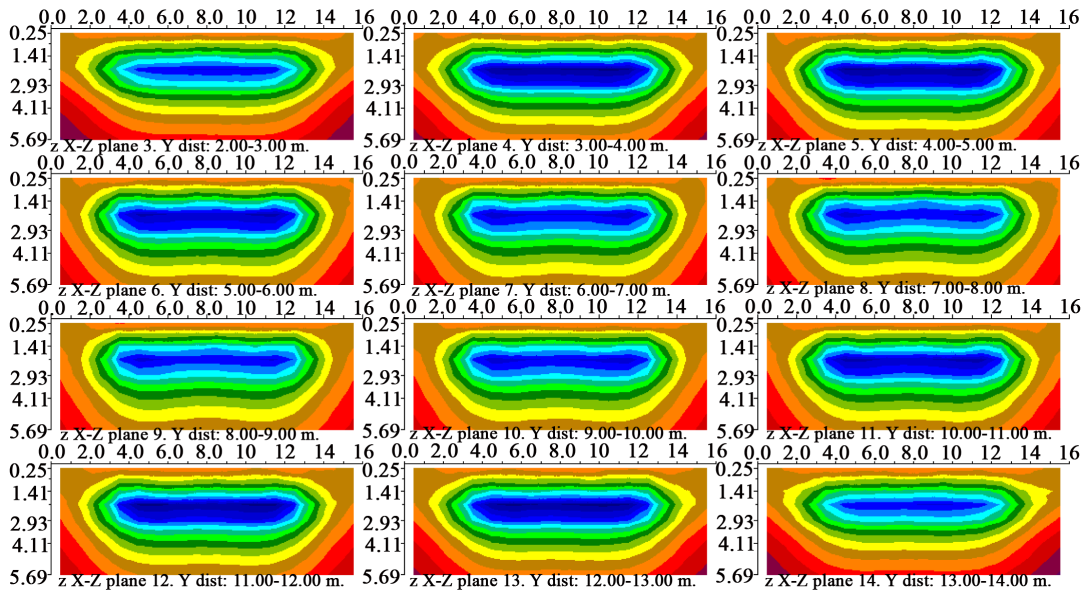

(b)

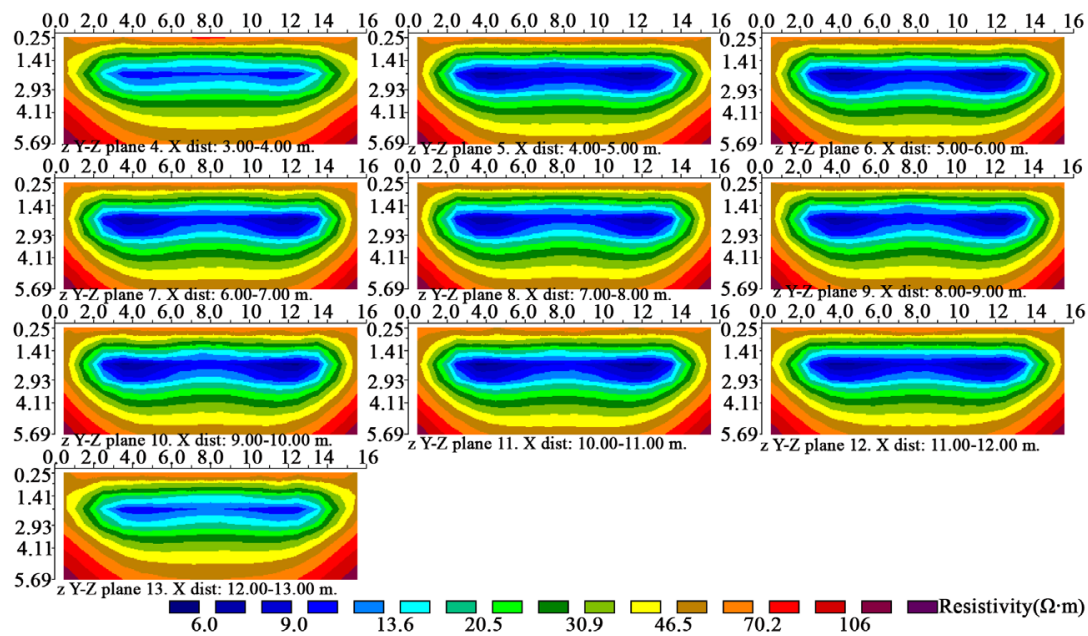

(c)

Figure 3. The resistivity distribution of weak structure plane underground water ((a), (b), (c) respectively expressed XY profile, XZ profile, YZ profile). (a) The horizontal plane of resistivity (xy); (b) the vertical surface of resistivity (xz); (c) the vertical surface of resistivity (yz). 


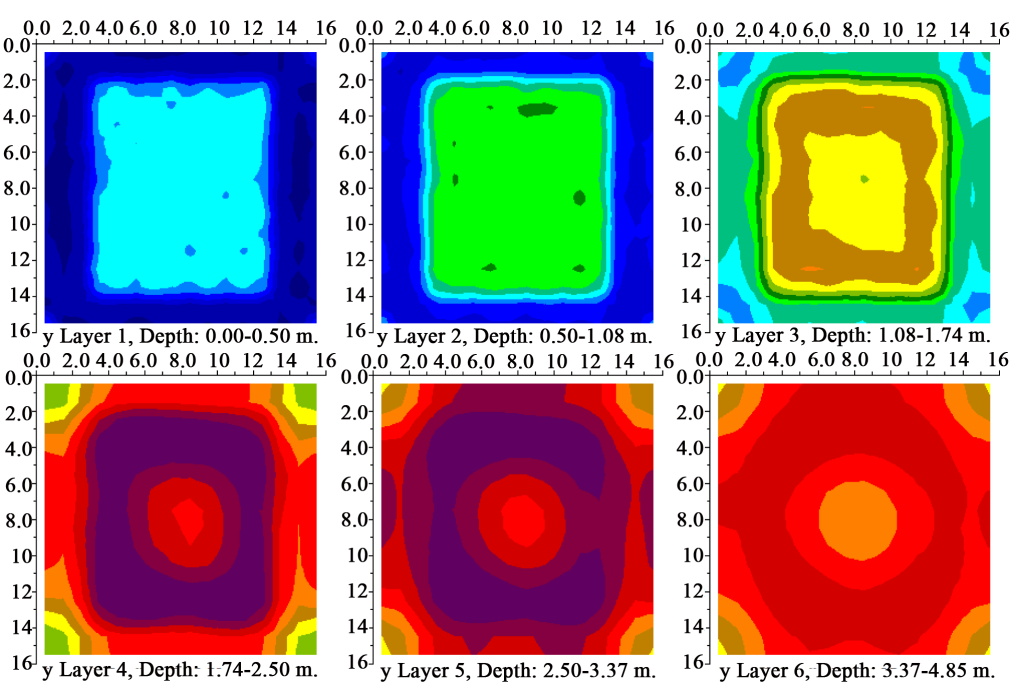

(a)

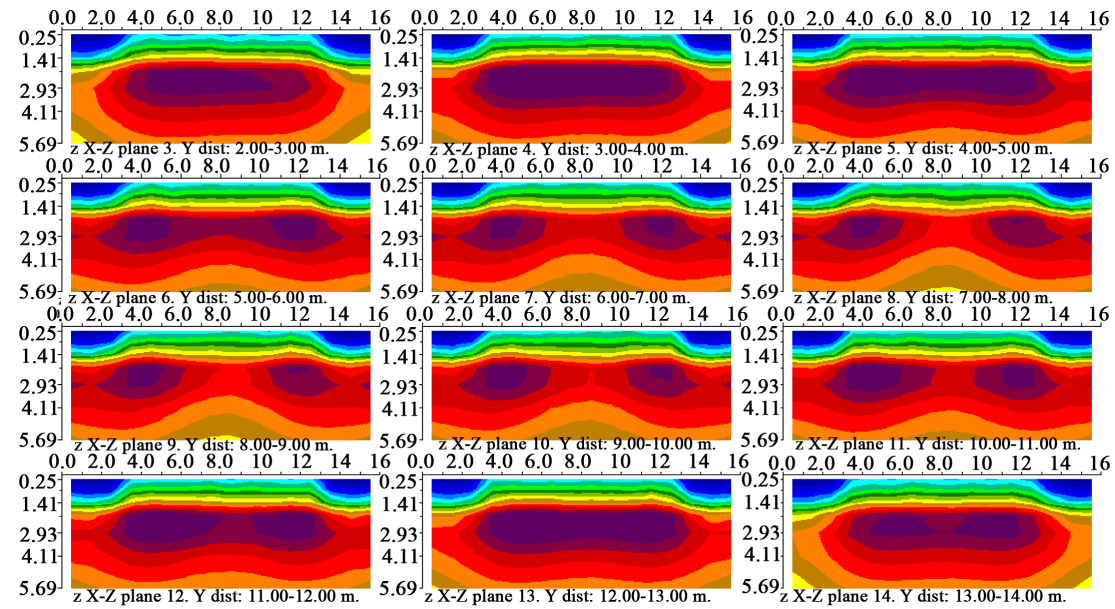

(b)

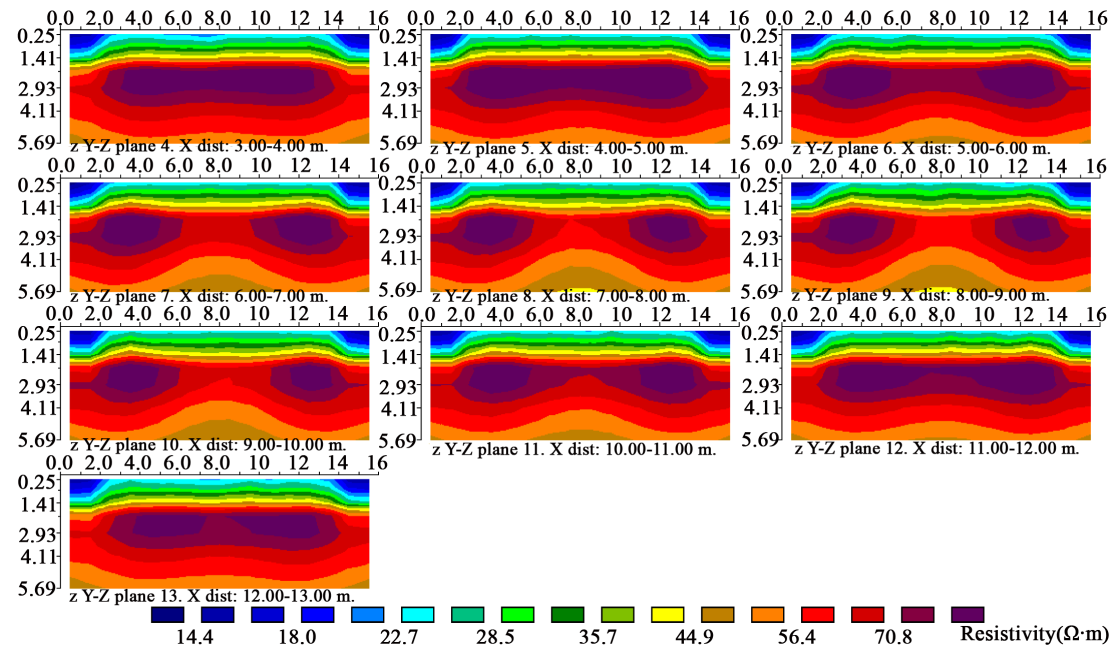

(c)

Figure 4. The resistivity distribution of weak structure plane without underground water ((a), (b), (c) respectively expressed $\mathrm{XY}$ profile, XZ profile, YZ profile). (a) The horizontal plane of resistivity (xy); (b) the vertical surface of resistivity (xz); (c) the vertical surface of resistivity (yz). 
$\mathrm{XY}$ resistivity distribution diagram, the weak structural plane of high resistance influence range is significantly larger can be found, but from the resistivity distribution shape were observed, in layer 4 to 5 resistivity distribution shape change from square to approximate circular, the high resistivity anomaly area and weak structural plane location are basically consistent can be judged in layer 4 . The high resistivity anomaly district about $12 \mathrm{~m}$ length, about $10 \mathrm{~m}$ wide, the result is consistent with the model, indicating that high resistance patterns of the weak structure plane reflected well. From the XZ resistivity distribution diagram shows that the high resistance anomaly area is about $10 \mathrm{~m}$ wide, and the thickness has some error, the shape of the high resistivity anomaly area is basically the same as the position and the size of the weak structure plane. From YZ resistivity distribution figure seen, high resistivity anomaly mayor $12 \mathrm{~m}$ length, thickness of some error, but the high resistivity anomaly zone and weak structural plane where position corresponding. By comparing with the resistivity characteristics of the weak structure plane underground water, the resistivity imaging resolution of the weak structure surface underground water is found to be higher, the reflection of weak structural plane is better.

\section{Image Processing}

The inversion after the data collated into image processing software, after partition model adjust chromatography, the action of groundwater and without groundwater of weak structural plane are extracted from the 3D resistivity images, as shown in Figure 5 and Figure 6. By adding rectangular coordinate system, we can observe

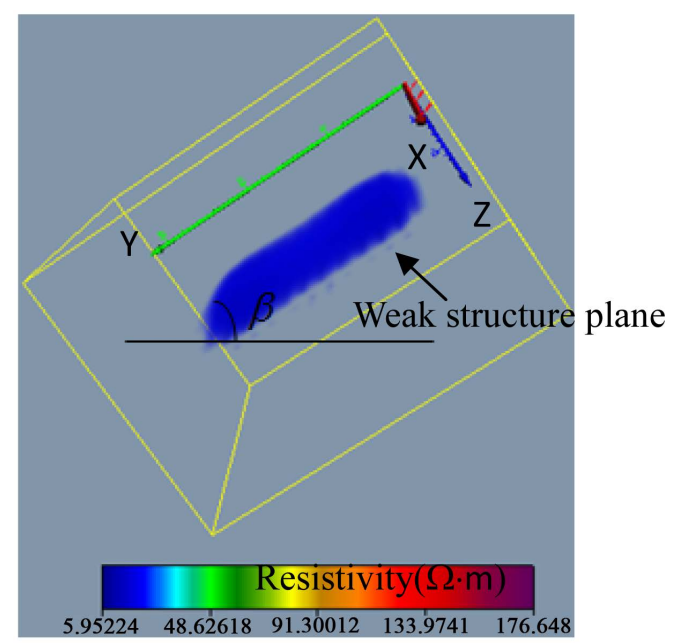

Figure 5. Three dimensional resistivity image of weak structure plane underground water.

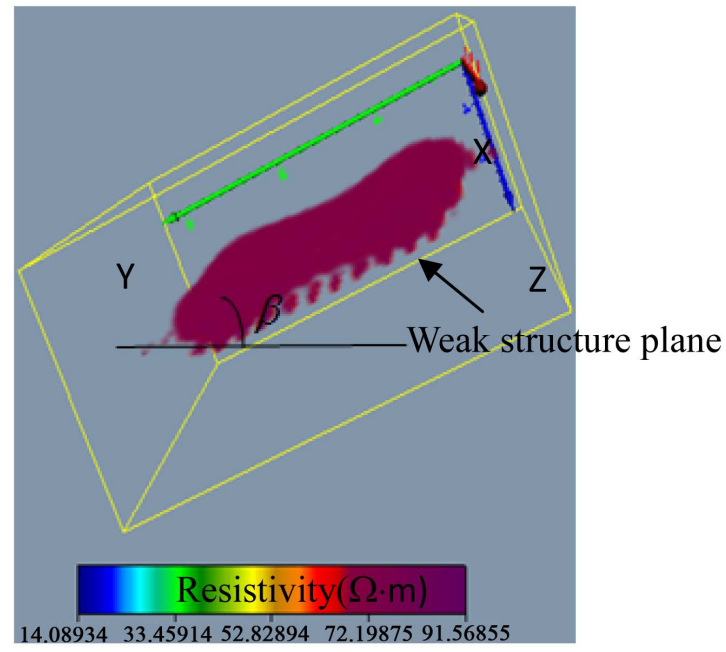

Figure 6. Three dimensional resistivity image of weak structure plane without underground water. 
the spatial form of the weak structure plane and estimate the size of the weak structure plane, weak structural plane has a higher accuracy under the action of groundwater, in the actual measurement can provide more accurate data, and the weak structural plane without ground water has a certain error, which needs to be reduced on the basis of the actual measurement. By measuring the angle between the weak structure plane and the horizontal direction, and use the formula:

$$
\sigma_{1} \cos \beta \sin \left(\varphi_{j}-\beta\right)+\sigma_{3} \sin \beta \cos \left(\varphi_{j}-\beta\right)+c_{j} \cos \varphi_{j} \geq 0
$$

where: $\sigma_{1}$ is principal stress; $\sigma_{3}$ is minor principal stress; $\beta$ is the angle between the weak structure plane and the horizontal; $\varphi_{j}$ is internal friction angle; $c_{j}$ is cohesion.

It can be used as a condition to judge the stability of rock slope, so as to make a reasonable safety evaluation for rock slope and provide scientific data for design and construction.

\section{Conclusions}

1) By means of three-dimensional electrical resistivity tomography numerical simulation of rock slope with weak structure plane, the electrical resistivity tomography resolution of the weak structure surface under different ground water is analyzed, illustrating the effectiveness of the three-dimensional electrical resistivity tomography in the detection of weak structural plane.

2) Three-dimensional electrical resistivity tomography overcomes the lack of 2D electrical resistivity tomography; the distribution of weak structural plane in rock slope can be found, judging the stability of rock slope, a rough estimate of unstable rock excavation amount; the result is intuitive and easy to explain.

3) In the numerical simulation of 3D electrical resistivity tomography of rock slope, the model is established without considering the influence of topography fluctuation on resistivity imaging, which should be worth attention in the future research. When the high resistance anomaly occurs, the weak structure plane is separated from the bedrock, and it should be properly reduced when estimating the amount of the landslide surface and the landslide. In the study of the mechanism of the instability of the soft surface, the relationship between the resistivity and the stress and strain of rock should be established.

\section{Acknowledgements}

This paper is funded by National Natural Science Foundation of China (51279219).

\section{References}

[1] Jin, D.L. (2000) Water Resources and Hydropower Engineering Geology Classification Slope (Mid). Northwest Water Electric, 2, 10-12.

[2] Gou, X.J., Jia, Y.G., Huang, X.Y. and Niu, J.J. (2004) Landslides Study the Use of High Density Resistivity Method. Chinese Journal of Rock Mechanics and Engineering, 23, 1662-1669.

[3] Zhang, Y.C. (2007) Study on Geophysical Feature of Slope Failure and Its Application. Zhongnan University, Changsha.

[4] Chen, J. (2014) High Density Electrical Prospecting Technique in Landslide Cause Slope Analysis. Northern Transportation, 10, 69-72.

[5] Zeyen, H., Pessel, M., Ledésert, B., Hébert, R., Bartier, D., et al. (2011) 3D Electrical Resistivity Imaging of the Near-Surface Structure of Mud-Volcano Vents. Tectonophysics, 509, 181-190. http://dx.doi.org/10.1016/j.tecto.2011.05.007

[6] Li, J.M. (2005) Electric Field and Electric Prospecting. Geological Publishing House, Beijing.

[7] Shi, L.Q., Zhai, P.H., Wei, J.Z., Zhu, L., Han, J., et al. (2008) Three-Dimensional High-Density Electrical Technique in Rock Rich Water Detection. Journal of Shandong University of Science and Technology, 27, 1-4. 


\section{Submit or recommend next manuscript to SCIRP and we will provide best service for you:}

Accepting pre-submission inquiries through Email, Facebook, LinkedIn, Twitter, etc.

A wide selection of journals (inclusive of 9 subjects, more than 200 journals)

Providing 24-hour high-quality service

User-friendly online submission system

Fair and swift peer-review system

Efficient typesetting and proofreading procedure

Display of the result of downloads and visits, as well as the number of cited articles

Maximum dissemination of your research work

Submit your manuscript at: http://papersubmission.scirp.org/ 